\title{
A novel, stable, helical scaffold as an alternative binder - construction of phage display libraries
}

\author{
Anna Cyranka-Czaja and Jacek Otlewski ${ }^{\bowtie}$ \\ Department of Protein Engineering, Faculty of Biotechnology, University of Wroclaw, Wrocław, Poland
}

\begin{abstract}
Specific, high affinity binding macromolecules are of great importance for biomedical and biotechnological applications. The most popular classical antibody-based molecules have recently been challenged by alternative scaffolds with desirable biophysical properties. Phage display technology applied to such scaffolds allows generation of potent affinity reagents by in vitro selection. Here, we report identification and characterization of a novel helical polypeptide with advantageous biophysical properties as a template for construction of phage display libraries. A three-helix bundle structure, based on Measles virus phosphoprotein $\mathrm{P}$ shows a very favourable stability and solubility profile. We designed, constructed and characterized six different types of phage display libraries based on the proposed template. Their functional size of over $10^{9}$ independent clones, balanced codon bias and decent display level are key parameters attesting to the quality and utility of the libraries. The new libraries are a promising tool for isolation of high affinity binders based on a small helical scaffold which could become a convenient alternative to antibodies.
\end{abstract}

Key words: alternative scaffold, phage display, construction of phage libraries

Received: 26 March, 2012; revised: 25 June, 2012; accepted: 20 August, 20912; avaialble on-line: 18 September, 2012

\section{INTRODUCTION}

The most important proteins showing specific molecular recognition are antibodies. The ability to interact with almost any antigen makes them genuinely universal binders. Immunoglobulin-based molecules represent the fastest growing class of biopharmaceuticals used both in therapy and diagnostics. However, because of their numerous limitations such as the large size, presence of disulphide bonds and low conformational stability, alternative scaffolds are badly needed (Binz et al., 2005; Skerra, 2007). Several attempts have been made to introduce alternative binders, from small helical domains (Nord et al., 1997; Nygren \& Uhlen, 1997; Nygren, 2008) and repetitive modules of Designed Ankyrin Repeat Proteins called DARPins (Binz et al., 2004; Tamaskovic et al., 2012) to the $\mathrm{Ig}$-like $\beta$-structure scaffold of fibronectin type III domain (Koide et al., 1998; Koide et al., 2007). The main advantage of these novel binding proteins is their robust structure, high stability and efficient bacterial expression. They have also been proven to exhibit binding properties comparable to those of antibodies (Wikman et al., 2004; Lendel et al., 2006; Orlova et al., 2006; Zahnd et al., 2006; Zahnd et al., 2007; Friedman et al., 2008; Milovnik et al., 2009).
The specific binding molecules are selected from combinatorial libraries based on a technology that enables linking phenotype with genotype. The combinatorial library can be presented using either conventional phage display method (Smith, 1985; Smith \& Scott, 1993) or in vitro based technologies like mRNA and ribosome display (Amstutz et al., 2001). Phage display has limitations in the library size (due to finite bacterial transformation efficiency) but, on the other hand, is much less demanding than the in vitro technologies. The main key to the success of phage selection is the size and quality of the library used for selection of specific binders (Ling, 2003).

Since the sequence diversity generated through randomization at several amino acid positions may lead to selection of variants with highly destabilized structure, it is accepted that scaffolds with favorable stability properties should be used as a template for phage display libraries (Nygren \& Uhlen, 1997).

One of the first proposed alternatives to immunoglobulins was domain Z from staphylococcal protein A, called affibody. This 58-aminoacid three-helix bundle protein, despite a flat paratope, has been proven by phage display to bind several targets with high specificity and affinity (Nygren, 2008). These favorable binding properties of the affibody encouraged us to look for a structurally similar scaffold and apply it to construct phage libraries.

In this publication we investigated the potential of Measles virus phosphoprotein $\mathrm{P}$ sequence that folds into a three-helix bundle structure as a protein scaffold for phage display libraries. We tested the expression level, solubility and denaturation parameters of this protein. We used this sequence to construct several phage libraries with different randomization types and translocation pathways. The libraries were fully characterized and initial selection was performed.

\section{MATERIAL AND METHODS}

Strains, vectors and enzymes. Escherichia coli strain DH10 was used for standard cloning, strain BL21(DE3) CodonPlus-RIL (Stratagene, USA) for expression of virus domains. Phage propagation was carried out in E. coli XL1-Blue (Stratagene). E. coli MC1061F' strain used for electroporation was obtained by standard mating protocol of E. coli MC1061 (Biorad) and XL1-Blue strains. Helper phage M13-VCS was obtained from Stratagene.

e-mail: otlewski@protein.pl 
Phagemid vector $\mathrm{pComb3}_{\mathrm{SS}}$ (Barbas, 1995) was a gift from Dr. C. F. Barbas (The Scripps Research Institute, La Jolla, CA) and pDST23 (Steiner et al., 2006) from Dr. A. Pluckthun (University of Zurich). Plasmid encoding Measles virus phosphoprotein $\mathrm{P}$ - pet21a/P (Longhi et al., 2003) was a gift from Dr. S. Longhi (CNRS, Marseille); that for Sendai virus phosphoprotein P from Dr. W.P. Burmeister (EMBL, Grenoble) (Blanchard et al., 2004). The TEV protease expression plasmid pTPSN was kindly provided by Dr. J. A. Doudna (Yale University, New Heaven, CT) (Lucast et al., 2001).

Restriction enzymes, ligase and polymerase were obtained from Fermentas, oligonucleotides from Metabion and GeneLink. The Gateway system (Invitrogen) was used for cloning of virus domains in vectors pDONR201 and pDEST15.

Cloning, expression and purification of virus domains. The analyzed virus domains correspond to:

Measles virus phosphoprotein P (P03422-1) XD fragment (458-507 aa);

Sendai virus phosphoprotein P (P1425-1) C subdomain (516-568 aa);

Mumps virus phosphoprotein P (P16072-1) nucleocapsid binding domain (343-391 aa).

The Mumps virus domain DNA sequence was generated by PCR with primers MumA, MumB and MumC. Sequences encoding virus domains with flanking regions containing attb1 and attb2 sites together with an rTEV cleavage site were obtained by standard two-step PCR with primers shown in Table 1 (Supplementary Materials at www.actabp.pl). After purification (PCR purification kit, A\&A Biotechnology), the PCR product was first cloned into the pDONR201 vector using the Gateway recombination system (Invitrogen). After restriction analysis the cloned genes were transferred into the expression vector pDEST15 by LR reaction (Invitrogen). The sequence of the coding region was checked by sequencing with the pGEX5 primer (Agowa, Germany).

Expression was done in E. coli BL21 (DE3) RIL strain in standard $\mathrm{LB}$ medium, till $\mathrm{OD}_{600}=0.7$ and then induced with $1 \mathrm{mM}$ IPTG for $12 \mathrm{~h}$ at $30^{\circ} \mathrm{C}$.

Bacterial pellet was resuspended in buffer A $(50 \mathrm{mM}$ Tris $\mathrm{pH} 8,200 \mathrm{mM} \mathrm{NaCl}, 5 \mathrm{mM}$ EDTA) sonicated $(5 \times 5$ min with $5 \mathrm{~min}$ breaks) on ice, and centrifuged. Soluble fraction was applied to equilibrated Glutathione Superflow resin (Amersham Biosciences) for $3 \mathrm{~h}$. Extensive washing was performed with buffer A and elution with $20 \mathrm{mM}$ GSH buffer. Collected fractions were analyzed by SDS/PAGE. Fractions with the fusion protein were pooled and dialysed against buffer B (50 mM Tris $\mathrm{pH}$ 8, $150 \mathrm{mM} \mathrm{NaCl}, 2 \mathrm{mM}$ DT', $1 \mathrm{mM}$ EDTA) and digested with rTEV protease. Digested protein was bound to glutathione resin $\left(1 \mathrm{~h} 4^{\circ} \mathrm{C}\right)$, the unbound fraction was concentrated (Amicon) and applied to size exclusion chromatography (Amersham Biosciences, Superdex 75) to get rid of the rTEV protease and traces of GST protein. Fractions containing virus domains were pooled and stored at $-80^{\circ} \mathrm{C}$ in buffer A. Purity of the protein was confirmed by SDS/PAGE (Laemmli, 1970) and mass spectra (Applied Biosystems AB 4800+ MALDI TOF/TOF).

Biophysical characterization. The folded state of the proteins was confirmed by $\mathrm{CD}$ spectra recorded in the wavelength range $200-270 \mathrm{~nm}$ in $10 \mathrm{mM}$ Tris buffer $\mathrm{pH} 7$ at $293 \mathrm{~K}$ on a Jasco J-715 spectropolarimeter. Thermal stability was measured by following changes in ellipticity at $222 \mathrm{~nm}$, using $10-\mathrm{mm}$ cuvette with a slit width set to $2 \mathrm{~nm}$ and a response time of $8 \mathrm{~s}$. Transition was monitored at a constant rate of $1 \mathrm{deg} / \mathrm{min}$.
Three different $\mathrm{pH}$ conditions were applied: $10 \mathrm{mM}$ Tris $\mathrm{pH}$ 7.0, $20 \mathrm{mM}$ sodium phosphate $\mathrm{pH} 5.6$, and $20 \mathrm{mM}$ glycine $\mathrm{pH}$ 2.9. Chemical denaturation of the protein at $15 \mu \mathrm{M}$ concentration was performed by incubation in various concentrations of $\mathrm{GdmCl}$ in Tris buffer at $20^{\circ} \mathrm{C}$ for $12 \mathrm{~h}$ followed by CD signal measurement (222 nm) in a $10-\mathrm{mm}$ cuvette. Data were analyzed using GraphPad Prism software assuming a two-state reversible equilibrium transition .

Construction of libraries. Primer sequences are shown in Table 2 (Supplementary Materials at www.actabp.pl) and the assembly scheme is presented in Fig. 1. For the NNC and HWC type of randomization two main primers (A and B for each library) were hybridized and then elongated with Klenow fragment exopolymerase $\left(1 \mathrm{~h}, 37^{\circ} \mathrm{C}\right)$. The product was extracted from agarose gel (Gel-out, A\&A Biotechnology) and used for two subsequent PCRs in order to obtain a full length randomized sequence with proper restriction sites. Ctype libraries, based on conventional pelB signal peptide, were cloned into $\mathrm{pComb3H}$ vector using $\mathrm{NcoI}$ and SpeI restriction sites. Bam HI and EcoRI restriction sites were used for cloning of S-type libraries employing SRP translocation pathway. In order to obtain a highly diversified set of final sequences, gradient PCR was applied. Randomized DNA fragments for the C4 and S4 libraries were obtained through amplification of the long primer BIBCS4GL in a standard PCR with the Cfor and CRev, SFor and SRev primers, respectively.

Ten micrograms of final, cleaned-up product and $20 \mu \mathrm{g}$ of vectors were digested at $37^{\circ} \mathrm{C}$ overnight. Ligation of purified digests was performed overnight at $17^{\circ} \mathrm{C}$ with T4 ligase. The mixture was subjected to phenol/ chloroform extraction and ethanol precipitation. DNA was dissolved in $100 \mu \mathrm{l}$ of sterile water and used for electroporation in ten shots.

Electrocompetent cells were prepared according to a standard protocol (Wojcik et al., 2010). Transfromants were grown on ten big (25-cm diameter) plates with $2 \times T Y$ medium supplemented with $1 \%$ glucose and antibiotic. Serial dilution in 2xTY medium was done to estimate the size of the library. Cells were scrapped from plates and libraries were kept at $-80^{\circ} \mathrm{C}$ as a glycerol stock. The library was grown in $2 \times \mathrm{TY}$ medium with an-
A

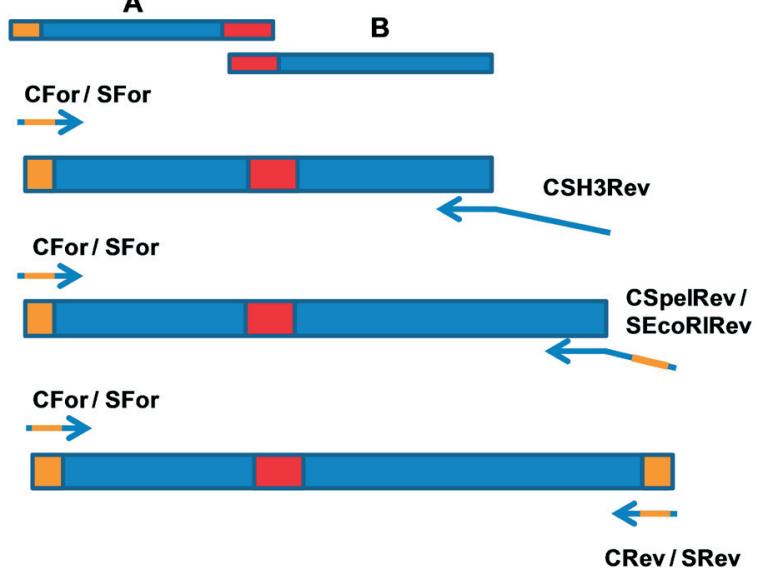

Figure 1. Assembly of randomized DNA fragments for construction of phage libraries

Complementary sequences used for hybridization of oligonucleotides $A$ and $B$ are marked in red, restriction sites used for cloning in orange. After hybridization (based on custom oligonucleotides), three subsequent PCR reactions were performed to obtain final product, applied for restriction. 
tibiotic and infected with helper phage M13-VCS. The phage was purified from bacterial supernatant by precipitation with PEG according to the standard protocol (Russel M, 2004). To allow functional display the phage was further amplified in the XL1-Blue strain and purified as described above. The Mv3 $\alpha$-displaying phage particles at the concentration of $1 \times 10^{13} \mathrm{cfu} / \mathrm{ml}$ were stored at $-80^{\circ} \mathrm{C}$, in PBS supplemented with $10 \%$ glycerol.

Characterization of libraries - size, quality, display. Thirty-six random clones from each library were isolated and sequenced (Agowa). PCR was also performed on random 20 clones from each library. To analyze the display of $\mathrm{Mv} 3 \alpha$ phage particles were analyzed by Western blotting with use of anti-pIII antibody (MobiTec). $10^{10}$ phages were subjected to SDS/PAGE and then transferred to PVDF membrane by a standard semi-dry protocol. The membrane was blocked with $5 \%$ BSA in TBS overnight, then incubated with a 1:1000 dilution of a primary antibody, washed and incubated with secondary anti-mouse HRP-conjugated antibody Jackson ImmunoResearch) at the 1:10000 dilution. SuperWest signal (Pierce) was used for signal detection. For SRP libraries mouse anti-FlagM2 (Sigma) antibodies were used.

Test selections. Human S100A7 was expressed as a fusion with GST from the pDEST15 vector and purified as described for the virus domains. Purity of the antigen was confirmed by SDS/PAGE and mass spectra analysis. For solid surface selection the target protein was immobilized on immunotubes overnight at $4^{\circ} \mathrm{C}$ in $100 \mathrm{mM} \mathrm{NaHCO} \mathrm{pH}_{3} 9.6$ at the concentration of $50 \mu \mathrm{g} / \mathrm{ml}$. Tubes were blocked by $1-\mathrm{h}$ incubation with $2 \%$ MPBS (PBS buffer containing 2\% powder milk) at room temperature. For the first round of selection $10^{13}$ phage particles were used, after $2 \mathrm{~h}$ of incubation (with rotation) unbound phage was removed by washing five times with PBST (PBS containing 0.1\% Tween) followed by five washes with PBS. Bound phage was eluted with $1 \mathrm{ml}$ of $100 \mathrm{mM}$ triethylamine for $8 \mathrm{~min}$ and neutralized with $0.5 \mathrm{ml}$ of $1 \mathrm{M}$ Tris $/ \mathrm{HCl} \mathrm{pH}$. Eluted phage particles were used for infection of exponentially growing E. coli XL1-Blue for $40 \mathrm{~min}$ at $37^{\circ} \mathrm{C}$. Centrifuged bacteria were grown overnight on large $2 \mathrm{TY}$ agar plates with $33 \mu \mathrm{g} / \mathrm{ml}$ chloramphenicol and $1 \%$ glucose. Bacterial lawn was scrapped from the plates and used for inoculation to $\mathrm{OD}_{600}=0.1$ of $200 \mathrm{~mL}$ of $2 \mathrm{TY}$ broth containing chloramphenicol and $1 \%$ glucose. After reaching $\mathrm{OD}_{600}=0.5$, bacteria were infected with $10^{10}$ helper phage at a final concentration of $10^{10}$, after centrifugation bacteria were resuspended in $2 \mathrm{TY}$ broth containing chloramphenicol, kanamycin and $0.1 \mathrm{mM}$ IPTG and grown overnight at $30^{\circ} \mathrm{C}$. $10^{12}$ purified phage particles were used for subsequent rounds of selection followed by ten washing steps with PBST and PBS each. Five rounds of panning were conducted.

For selection in solution the antigen was biotinylated with EZ-link Sulfo-NHS-SS-biotin (Pierce) according to the manufacture's instructions. The level of biotinylation was estimated by mass spectrometry. All tubes used for selection were blocked with $0.1 \%$ gelatin in PBS. Before each round of panning negative preselection was performed - phage particles were incubated with preblocked streptavidin-coated magnetic beads Dynabeads (Invitrogen) for $1 \mathrm{~h}$ at RT with end to end rotation. For selection the phage was incubated with the biotinylated agent in $0.1 \%$ gelatin PBS, followed by 15 -min incubation with Dynabeads to capture the phage-antigen complexes. After washing the Dynabeads with PBST and PBS the bound phage particles were eluted by incubation in $100 \mathrm{mM}$ DTT in PBS for $15 \mathrm{~min}$ at RT. The amount of antigen used was decreased from round to round, while the washing conditions were progressively more stringent. Binding to the antigen was performed at RT or $4^{\circ} \mathrm{C}$, depending on the round. Details of the selection conditions are given in Table 3.

Polyclonal phage ELISA. Polyclonal phage ELISA was performed for both solid phase and in-solution selection. A pool of $10^{10}$ phage particles after each round of panning was incubated for $2 \mathrm{~h}$ at RT with the immobilized antigen (directly — for MaxiSorp selection or indirectly via streptavidin - for Dynabeads). As a control, phage was incubated in wells with buffer alone or with streptavidin. After washing with PBST and PBS, anti-M13 HRP-conjugated antibodies (Amersham Biosciences) were added for $1 \mathrm{~h}$ at RT. Another step of washing was performed and the amount of bound phage was detected with TMB solution (Sigma). The reaction with HRP was stopped with $1 \mathrm{M} \mathrm{H}_{3} \mathrm{PO}_{4}$ (Sigma) and determined colorometrically.

\section{RESULTS AND DISCUSSION}

\section{Choosing scaffold}

We applied MSDfold software to identify protein domains with high structural similarity to the protein $Z$ specific affibody for which the crystal structure is known (PDB code 1lp1/a). We identified three sequences of phosphoprotein P from Measles, Sendai and Mumps viruses that form 50-aminoacid helical domains with no sequence similarity to the affibody. The coding sequences of the virus domains were cloned into the pDEST15 vector enabling expression with a GST tag. The proteins were purified with affinity chromatography on glutathione resin, then the GST-tag was removed using rTEV protease and the final purification step was performed by size exclusion chromatography. The expression level for all three domains was high and the proteins were soluble (Fig. 2 - Supplementary Materials at www.actabp.pl). All three proteins were monomeric as judged from their size exclusion chromatography profiles (data not shown). The yield was about 15 to $20 \mathrm{mg}$ of purified protein per 1 liter of culture. The purity assessed by SDS/PAGE and mass spectra analysis exceeded $97 \%$.

Stability studies of the three domains were performed by thermal and chemical denaturation monitored by the CD signal at $222 \mathrm{~nm}$. In agreement with recent results (Kingston et al., 2008) the Mumps virus domain had a poor stability profile and formed a molten globule in solution at $\mathrm{pH} 7.0$ (data not shown), therefore it was excluded from further studies. The stability parameters of the Measles protein at pH 7.0 could not be assessed by CD spectra, as the thermal transition was not com-

Table 3. In-solution panning conditions.

The concentration of target protein was decreased gradually to favor high affinity binders. Every other round the binding was performed overnight and the number of washes were increased after each round.

\begin{tabular}{llll}
\hline Round & $\begin{array}{l}\text { Antigen } \\
\text { concentration }\end{array}$ & Binding & Washing \\
\hline 1 & $100 \mathrm{nM}$ & $48 \mathrm{~h}, 4^{\circ} \mathrm{C}$ & 3xPBST, 1xPBS \\
2 & $50 \mathrm{nM}$ & $1 \mathrm{~h} 40 \mathrm{~min}, \mathrm{RT}$ & 5 xPBST, 2xPBS \\
3 & $25 \mathrm{nM}$ & $\mathrm{ON} 4^{\circ} \mathrm{C}, 1 \mathrm{~h} \mathrm{RT}$ & $8 \times \mathrm{PBST}, 2$ xBS \\
4 & $10 \mathrm{nM}$ & $1 \mathrm{~h} 45 \mathrm{~min}, \mathrm{RT}$ & 9xPBST, 1xPBS \\
5 & $5 \mathrm{nM}$ & $\mathrm{ON} 4^{\circ} \mathrm{C}, 1 \mathrm{~h} \mathrm{RT}$ & $15 \times \mathrm{PBST}, 1 \times \mathrm{PBS}$ \\
\hline
\end{tabular}


Table 4. Thermodynamic parameters of Measles and Sendai domain unfolding Both thermal and chemical denaturation parameters are presented. Details of experiments are described in the Methods section.

\begin{tabular}{|c|c|c|c|c|}
\hline & \multicolumn{2}{|c|}{ Measles virus domain } & \multicolumn{2}{|c|}{ Sendai virus domain } \\
\hline & $\mathrm{T}_{\mathrm{den}}\left({ }^{\circ} \mathrm{C}\right)$ & $\Delta \mathrm{H}_{\mathrm{den}}(\mathrm{kcal} / \mathrm{mol})$ & $\mathrm{T}_{\mathrm{den}}\left({ }^{\circ} \mathrm{C}\right)$ & $\Delta \mathrm{H}_{\text {den }}(\mathrm{kcal} / \mathrm{mol})$ \\
\hline $\mathrm{pH} 7.0$ & $>85$ & $>40$ & 47.2 & 30.5 \\
\hline pH 5.6 & $>81$ & $>30$ & 37. & 24.5 \\
\hline pH 2.9 & 49.09 & 26.2 & 41.9 & 34.7 \\
\hline \multirow{3}{*}{$\begin{array}{l}\mathrm{pH} 2.9 \\
200 \mathrm{mM} \mathrm{NaCl}\end{array}$} & 63.05 & 29.5 & n.d. & n.d. \\
\hline & $\mathrm{GdmCl}_{1 / 2}(\mathrm{M})$ & $\Delta \mathrm{G}_{\mathrm{den}}(\mathrm{kcal} / \mathrm{mol})$ & $\mathrm{GdmCl}_{1 / 2}(\mathrm{M})$ & $\Delta \mathrm{G}_{\text {den }}(\mathrm{kcal} / \mathrm{mol})$ \\
\hline & 4.21 & 6.27 & 2.19 & 1.91 \\
\hline
\end{tabular}

pleted up to $95^{\circ} \mathrm{C}$ and $T_{\text {den }}$ value could only be estimated to be above $80^{\circ} \mathrm{C}$ (Fig. 3B). At this $\mathrm{pH}$ the Sendai domain showed a much lower $T_{\text {den }}$ of $47.2^{\circ} \mathrm{C}$. The $[\mathrm{GdmCl}]_{1 / 2}$ values obtained from chemical denaturation at $\mathrm{pH} 7.0$ were significantly lower for the Sendai than for the Measles domain: $2.2 \mathrm{M}$ and $4.2 \mathrm{M}$, respectively. In agreement, the stability expressed as $\Delta \mathrm{G}^{\mathrm{H}_{2} \mathrm{O}}$ den was much higher for the Measles domain than the Sendai one: $6.2 \mathrm{kcal} / \mathrm{mol}$ and $1.9 \mathrm{kcal} / \mathrm{mol}$, respectively (Table 4).

To assess the $\mathrm{T}_{\text {den }}$ of the Measles protein more exactly we analyzed temperature-induced transitions at a lower $\mathrm{pH}: 20 \mathrm{mM}$ Gly $\mathrm{pH} 2.9$ or $10 \mathrm{mM}$ phosphate $\mathrm{pH}$ 5.6 (Fig. 3 and Table 4). While at
Measles protein could still not be $\mathrm{pH} 5.6$ the $T_{\text {den }}$ of the Measles protein could still not be precisely determined, it was well over $40^{\circ} \mathrm{C}$ higher than that for the Sendai domain. At pH 2.9 the difference of $T_{\text {den }}$ between the two domains was $12^{\circ} \mathrm{C}$. We also observed that the stabilty of the Measles virus domain in the harsh conditions of $\mathrm{pH} 2.9$ could be easily improved by adding $\mathrm{NaCl}$ to $200 \mathrm{mM}$ (Fig. 3 and Table 4).

Thus, the three domains studied, despite their structural and functional similarity, revealed completely different stability properties, from the molten globule of Mumps domain through the medium stable Sendai protein to the remarkably stable Measles domain. The latter domain with its superb stability properties was chosen as the template for library construction.

\section{Design of libraries}

The main concern in designing libraries was to keep a balance between the theoretical and achievable library size to allow the majority of library sequences to undergo selection. The binding potential of an affibody is based on 13 amino acids located at two of the three helices that form a flat binding surface. Although different from the antibody CDRs (Complementarity Determining Region), the affibody binding surface buries a similarly large surface area of about $1650 \AA^{2}$ in the complex with a target macromolecule and forms eight or nine $\mathrm{H}$ bonds (Lendel et al., 2006). The key aspect in library construction is to efficiently design sequence diversity, meaning a rational introduction of randomized positions with respect to the structural nature of the scaffold and the library size limited by the bacterial transformation efficiency. Thus, our main goal in the library design was to limit their theoretical size in order to obtain representative libraries.

Since full randomization of 13 positions gives an unrealistic number of amino acid sequences (about $8.2 \times 10^{16}$ ) we decided to randomize only eight amino acid positions that appear to be crucial for the interaction with a target according to the available crystal structures of affibody complexes (Wahlberg et al., 2003; Lendel et al., 2006). The eight randomized positions include those that are in the binding hot spot and form hydrogen bonds with the target molecule. By applying the hard randomization scheme NNC to those eight amino acid positions we limited the theoretical library size to $2 \times 10^{9}$, which can be achieved by bacterial transformation (Table 5).
Figure 3. Normalized denaturation curves of virus domains (A) Thermal denaturation of Sendai virus domain; (B) Thermal denturation of Measles virus domain; (C) chemical unfolding of both domains. For curve analysis GraphPad software was applied. Changes in ellipticity were monitored at $222 \mathrm{~nm}$ wavelength, the protein concentration in solution was $6 \mu \mathrm{M}$. For thermal denaturation experiments, different buffer conditions were applied - as indicated by colors on the graphs. Details of experiment are given in Methods section. 
Table 5. Types of randomization and theoretical size of designed libraries

The randomization scheme is described by the degenerated nucleotides, where each letter represents different set of nucleotides: $N-A, C, G$ or $T ; K-G$ or $T ; M-A$ or $C ; H-A, C$ or $T ; W-A$ or T.

\begin{tabular}{|c|c|c|c|}
\hline Library & Transloaction pathway & Randomization & Theoretical size \\
\hline $\mathrm{C} 4$ & Sec - pelB & \multirow{2}{*}{$\frac{\mathrm{KMT}}{11 \text { positions }}$} & \multirow{2}{*}{$\begin{array}{l}4^{11} \\
4 \times 10^{6}\end{array}$} \\
\hline S4 & $\mathrm{SRP}-\mathrm{DsbA}$ & & \\
\hline $\mathrm{C6}$ & Sec - pelB & \multirow{2}{*}{$\begin{array}{l}\text { HWC }-\mathrm{N} / \mathrm{I} / \mathrm{H} / \mathrm{L} / \mathrm{Y} / \mathrm{F} \\
11 \text { positions }\end{array}$} & \multirow{2}{*}{$\begin{array}{l}6^{11} \\
8 \times 10^{9}\end{array}$} \\
\hline S6 & $\mathrm{SRP}-\mathrm{DsbA}$ & & \\
\hline C15 & $\mathrm{Sec}-$ pelB & \multirow{2}{*}{$\begin{array}{l}\text { NNC }-A / C / D / F / G / H / I / L / N / P / R / S / T / N / Y \\
8 \text { positions }\end{array}$} & \multirow{2}{*}{$\begin{array}{l}15^{8} \\
2 \times 10^{9}\end{array}$} \\
\hline S15 & $\mathrm{SRP}-\mathrm{DsbA}$ & & \\
\hline
\end{tabular}

We also used two soft HWC and KMT schemes of randomization (for details of the randomization schemes, see Table 5).

The soft randomization KMT allowing only four amino acids: Tyr, Ala, Ser, Asp was proposed based on the generation of low-nanomolar antibody mimics obtained from four amino acid code libraries by the Sidhu's and Kossiakoff's groups (Fellouse et al., 2004; Sidhu \& Kossiakoff, 2007). It was also shown that such minimal diversity allows selection of high-performance single-domain binders (Koide et al., 2007). Using this scheme we randomized 11 positions which led to the library size of $4^{11}\left(=4 \times 10^{6}\right)$ amino acid sequences. A slightly higher diversity level was obtained applying HWC randomization that allows a different set of amino acids (mainly hydrophobic ones) but still includes Tyr that is well known to be important in protein-protein interactions (Fellouse et al., 2006). We intentionally excluded from our soft randomization schemes proline, which is highly unfavorable for helices, to avoid destabilizing effects.

It is known that stable, rapidly folding proteins may fail to display efficiently on the phage surface due to their premature folding in the periplasm. To overcome this limitation the SRP phage display system was introduced for construction of phage libraries based on highly stable proteins (Steiner et al., 2006). This has been proven to improve the level of protein display by using a cotranslational (as opposed to the conventionally used post-translational) translocation pathway (Steiner et al., 2008). Therefore we constructed our libraries both in a conventional way (pelB leader) and in the SRP phage display system. Depending on the translocation type and randomization scheme we named the libraries $C$ for conventional phage display and S for SRP; followed by the number of different amino acids introduced in the randomized positions (e.g. C4, S4, etc.) The final concept
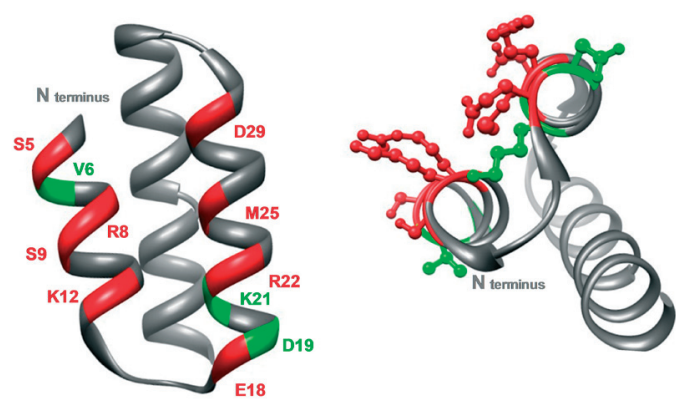

Figure 4. The spatial structure of Mv3a (10ksA)

Eight positions chosen for NNC randomization are highlighted in red. The three green ones are additional sites for a limited diversification of a total of 11 positions. The structure was generated by the Chimera software. a protein fused to the pIII coat protein of M13 pla To construct libraries, a total of $20 \mu \mathrm{g}$ of randomized, restricted DNA fragment corresponding to each type of library was ligated into a double-digested phagemid. Desalted ligation mixture was electroporated into freshly prepared electrocompetent E. coli MC1061F' cells. The main parameters influencing the procedure efficiency concerned the amount of electroporated DNA and the quality of electrocompetent cells. The highly electrocompetent strain MC1061F' provided high electroporation yield. A detailed protocol of library construction is available in the Methods section.

Quality of the libraries was assessed by PCR, DNA sequencing, Western blots and test selections.

The most significant feature of a phage library is the number of individual colonies. For all of the constructed libraries their size was estimated by serial dilutions after electroporation (Table 6). Plasmid DNA from 36 random colonies was sequenced for each library. Different colonies were subjected to PCR screening to confirm the correct size of cloned insert (around $170 \mathrm{nt}$ ). All the libraries had an outstanding level (over $80 \%$ ) of correct sequences (Table 6) and a well-balanced codon composition (Fig. 5), regardless of the method of sequence randomization. Usually a multi-step DNA synthesis (as for libraries C6, S6, C15 and S15) results in unfavorable library properties, such as a high content of incorrect sequences and uneven codon bias. Owing to the highquality of the DNA primers used for library construction and optimized PCR conditions, we achieved a satisfactory standard of the libraries at the DNA level.

\section{Western blotting}

Initially all the libraries were constructed in the phagemid vector $\mathrm{pComb} 3 \mathrm{H}$ that uses the conventional, post-translational translocation route. However, our preliminary experiments found a very low presentation level

Table 6. Analysis of constructed Mv3a libraries

Number of individual colonies was calculated by serial dilution after electroporation. The level of correct sequences was verified by sequencing 36 random clones from each library.

\begin{tabular}{lcc}
\hline Library & $\begin{array}{c}\text { Number } \\
\text { of individual colonies }\end{array}$ & $\begin{array}{c}\text { Percentage } \\
\text { of proper sequences }\end{array}$ \\
\hline C4 & $1 \times 10^{10}$ & 85 \\
S4 & $1 \times 10^{9}$ & 80 \\
C6 & $2.4 \times 10^{9}$ & 83 \\
S6 & $4.8 \times 10^{9}$ & 80 \\
C15 & $4.3 \times 10^{9}$ & 83 \\
S15 & $6 \times 10^{9}$ & 86 \\
\hline
\end{tabular}




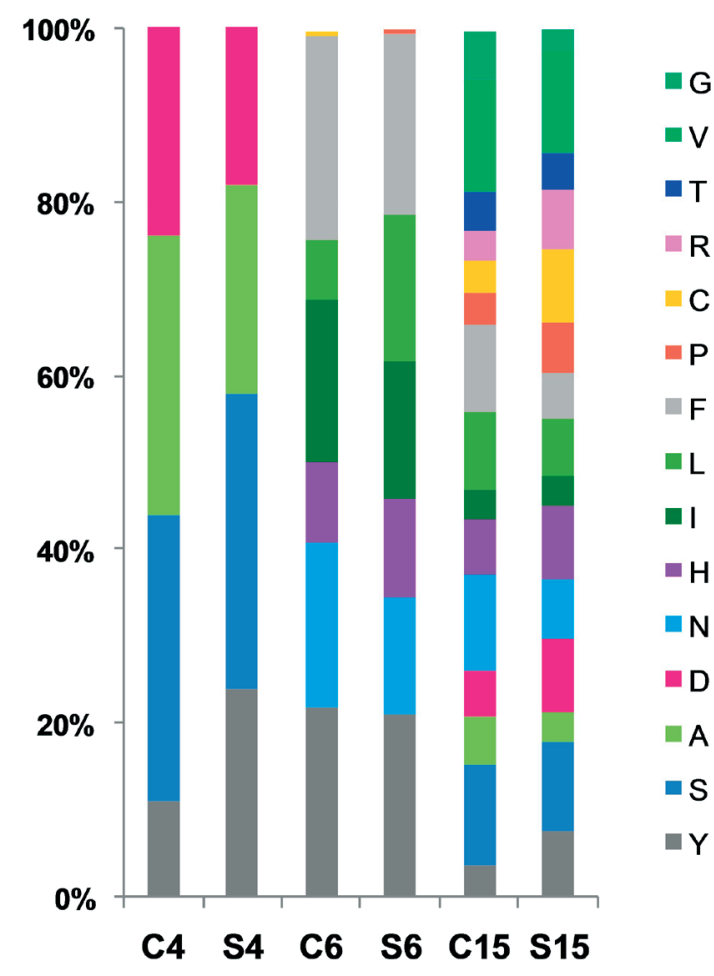

Figure 5. Codon bias of constructed libraries

Frequency of occurrence of each amino acid in randomized positions is shown. Colors correspond to the character of amino acid: green - nonpolar, aliphatic; blue: polar, uncharged; purple: polar, charged; grey: aromatic side chain. The chart is based on the sequencing results of random clones from each library type.

of the helical scaffold and poor selections results. It has been reported (Steiner et al., 2006) that stable, fast-folding proteins do not display efficiently via the sec pathway on the phage particle due to their premature folding. Therefore, we decided to use the SRP phage display system which employs cotranslational translocation of the presented protein. To compare the two different translocation pathways we subjected purified phages to Western blot analysis using anti-pIII antibodies for all libraries and also anti-Flag M2 antibodies for the S-type libraries.

C4 C6 C15 S4 S6 S15

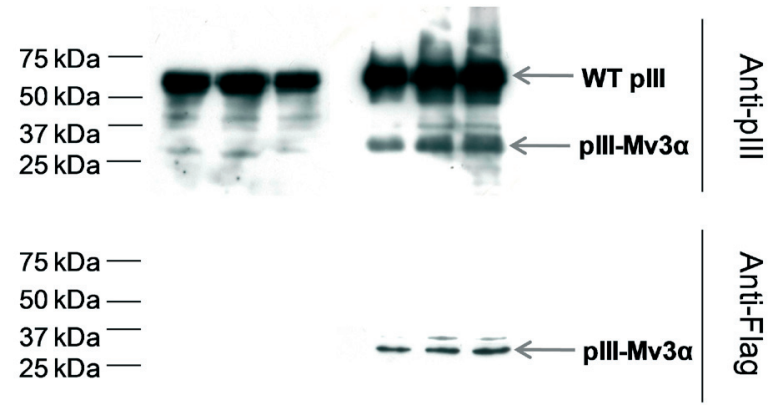

Figure 6. Western blot analysis of Mv3a libraries

Purified phage particles were separated by SDS/PAGE, blotted onto PVDF membrane and detected with antibodies specific for protein III. For S-type libraries also anti-Flag antibody was applied. Wild type plll is a 56-kDa protein, whereas the plll fragment expressed from phagemid vector is a molecule of around $25 \mathrm{kDa}$, therefore the Mv3a-plll fusion is around $31 \mathrm{kDa}$.
From the ratio of intensities of bands corresponding to pIII and pIII-Mv3 $\alpha$ we estimated that the SRP system allowed around five-fold improvement of the display yield (Fig. 6). The high stability of $\mathrm{Mv} 3 \alpha$ protein affected its presentation efficency, which can be observed on the blots. We assume that the cotranslational translocation system prevents premature folding of the stable threehelix bundle and thus affords its better display on the phage particle.

\section{Test selections}

To confirm the binding properties of $\mathrm{Mv} 3 \alpha$ we performed test selections. We decided to use human S100A7 (psoriasin), a cytoplasmatic protein highly upregulated in many types of cancer (Emberley et al., 2004; Kesting et al., 2009; Morgan et al., 2011). As the SRP system gave a better display we decided to run the test selection with the S4 library, both on immunotubes and in solution with biotinylated targets. The biotinylation agent containing a disulfide bond allowed specific elution conditions - by reduction in $100 \mathrm{mM}$ DTT. We applied mass spectra analysis to estimate the biotinylation level. For the panning procedure the target protein with one to three sites of biotinylation was apllied. The enrichment ratio was satisfactory only for the selections with Dynabeads. To assess the accuracy of the selection procedure we performed polyclonal phage ELISA using phage pools after each round of selection (Fig. 7). We estimated the amount of phage bound to the target using anti-M13 HRP-conjugated antibodies. The antigen was immobilized directly on Maxisorb wells for analysis of solid surface selection or via streptavidin in the case of Dynabead panning. The experiment confirmed that selection in solution was significantly more effective. To avoid the enrichment of non-specific binders we optimized the panning procedure by applying negative preselection on streptavidin beads and using gelatin as a blocking agent (Table 3). This strategy led to the most satisfactory selection results that are presented here (Fig. 7).

The above-mentioned properties of the Mv3 $\alpha$ libraries show that all crucial requirements for the construction of a functional phage library have been met. We achieved

\section{Polyclonal phage ELISA}

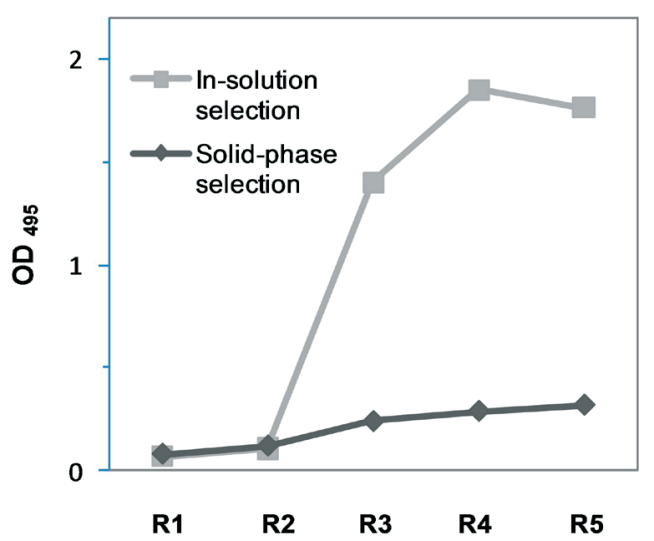

Figure 7. Polyclonal phage ELISA

Phage pool after each round of panning was applied for the binding assay towards S100A7. Y axis shows OD ${ }_{495}$ difference between probe and control well. For solid-phase selection well with buffer was used as negative control, for Dynabeads - streptavidin-coated surface. 
an ultimate bacterial transformation efficiency (up to $10^{10}$ ), which resulted in a favorable size of the obtained libraries. Moreover, the functional size of the libraries, which depends on the actual percentage of the correct sequences was unexpectedly high. The reported fraction of proper clones typically does not exceed $60 \%$, which is sufficient to apply the phage library for selection procedure (Binz \& Pluckthun, 2005). Our libraries were substantially better with over $80 \%$ of correct sequences. This limited the enrichment of defective molecules and increased the chances of isolation of high-affinity binders. The balanced codon bias of the randomized positions, as observed in the Mv3 $\alpha$ libraries, also contributed to the positive outcome of the panning experiments.

The Mv3 $\alpha$ libraries based on a vector containing a signal sequence for SRP translocation gave a better display level than the libraries constructed in the conventional phage system. So far, the SRP phage display has successfully been applied for construction of DARPin (Steiner et al., 2006) and fibronectin type III domain libraries (Koide et al., 2007; Wojcik et al., 2010). In this paper we showed that three-helix bundle domains are yet another group of proteins which can be efficiently presented on filamentous phage via the cotranslational route.

Our preliminary panning experiments showed that partial protein denaturation on the solid surface limits the enrichment of specific binders. Alternative use of a biotinylated target allowed us to perform selection in solution. The efficiency of biotinylation was strictly controlled: an excess of biotin on the protein surface can cause its partial unfolding or mask the potential binding sites. Using negative preselection on streptavidin-coated beads before each selection round we eliminated the straptavidin-specific clones. These precautions were necessary for proper enrichment, as confirmed by polyclonal phage ELISA. As for any phage library, a comprehensive analysis of panning conditions needs to be performed. Our preliminary results of the S100A7 selection of the S4 Mv3 $\alpha$ library can be applied to other libraries and to different antigens.

In conclusion, we introduced a novel, stable, helical scaffold for construction of phage libraries. Different types of randomization and translocation systems were tested. We characterized six $\mathrm{Mv} 3 \alpha$ libraries and tested the panning conditions. The results of this work demonstrate the feasibility of isolating specific Mv3 $\alpha$ binders which, owing to their favourable properties, should become a useful affinity tool.

\section{Acknowledgements}

This work was supported by the Ministry of Science and Higher Education - grant NN 302252233.

\section{REFERENCES}

Amstutz P, Forrer P, Zahnd C, Pluckthun A (2001) In vitro display technologies: novel developments and applications. Curr Opin Biotechnol 12: 400-405.

Barbas CF 3rd (1995) Synthetic human antibodies. Nat Med 1: 837839.

Binz HK, Amstutz P, Kohl A, Stumpp MT, Briand C, Forrer P, Grutter MG, Pluckthun A (2004) High-affinity binders selected from designed ankyrin repeat protein libraries. Nat Biotechnol 22: 575-582.

Binz HK, Amstutz P, Pluckthun A (2005) Engineering novel binding proteins from nonimmunoglobulin domains. Nat Biotechnol 23: 1257-1268.

Binz HK, Pluckthun A (2005) Engineered proteins as specific binding reagents. Curr Opin Biotechnol 16: 459-469.

Blanchard L, Tarbouriech N, Blackledge M, Timmins P, Burmeister WP, Ruigrok RW, Marion D (2004) Structure and dynamics of the nucleocapsid-binding domain of the Sendai virus phosphoprotein in solution. Virology 319: 201-211.

Emberley ED, Murphy LC, Watson PH (2004) S100A7 and the progression of breast cancer. Breast Cancer Res 6: 153-159.

Fellouse FA, Barthelemy PA, Kelley RF, Sidhu SS (2006) Tyrosine plays a dominant functional role in the paratope of a synthetic antibody derived from a four amino acid code. J Mol Biol 357: 100-114.

Fellouse FA, Wiesmann C, Sidhu SS (2004) Synthetic antibodies from a four-amino-acid code: a dominant role for tyrosine in antigen recognition. Proc Natl Acad Sci USA 101: 12467-12472.

Friedman M, Orlova A, Johansson E, Eriksson TL, Hoiden-Guthenberg I, Tolmachev V, Nilsson FY, Stahl S (2008) Directed evolution to low nanomolar affinity of a tumor-targeting epidermal growth factor receptor-binding affibody molecule. J Mol Biol 376: 1388-1402.

Kesting MR, Sudhoff H, Hasler RJ, Nieberler M, Pautke C, Wolff KD, Wagenpfeil S, Al-Benna S, Jacobsen F, Steinstraesser L (2009) Psoriasin (S100A7) up-regulation in oral squamous cell carcinoma and its relation to clinicopathologic features. Oral Oncology 45: 731-736.

Kingston RL, Gay LS, Baase WS, Matthews BW (2008) Structure of the nucleocapsid-binding domain from the mumps virus polymerase; an example of protein folding induced by crystallization. J Mol Biol 379: 719-731.

Koide A, Bailey CW, Huang X, Koide S (1998) The fibronectin type III domain as a scaffold for novel binding proteins. $J$ Mol Biol 284: 1141-1151.

Koide A, Gilbreth RN, Esaki K, Tereshko V, Koide S (2007) Highaffinity single-domain binding proteins with a binary-code interface. Proc Natl Acad Sci USA 104: 6632-6637.

Laemmli UK (1970) Cleavage of structural proteins during the assembly of the head of bacteriophage T4. Nature 227: 680-685.

Lendel C, Dogan J, Hard T (2006) Structural basis for molecular recognition in an affibody:affibody complex. J Mol Biol 359: 1293-1304.

Ling MM (2003) Large antibody display libraries for isolation of highaffinity antibodies. Combinatorial Chemistry \& High Throughput Screening 6: $421-432$.

Longhi S, Receveur-Brechot V, Karlin D, Johansson K, Darbon H, Bhella D, Yeo R, Finet S, Canard B (2003) The C-terminal domain of the measles virus nucleoprotein is intrinsically disordered and folds upon binding to the C-terminal moiety of the phosphoprotein. J Biol Chem 278: 18638-18648.

Lucast LJ, Batey RT, Doudna JA (2001) Large-scale purification of a stable form of recombinant tobacco etch virus protease. BioTechniques 30: 544-546 548-550 passim.

Milovnik P, Ferrari D, Sarkar CA, Pluckthun A (2009) Selection and characterization of DARPins specific for the neurotensin receptor 1. Protein Engineering Design \& Selection 22: 357-366.

Morgan MR, Jazayeri M, Ramsay AG, Thomas GJ, Boulanger MJ, Hart IR, Marshall JF (2011) Psoriasin (S100A7) associates with integrin beta6 subunit and is required for alphavbeta6-dependent carcinoma cell invasion. Oncogene 30: 1422-1435.

Nord K, Gunneriusson E, Ringdahl J, Stahl S, Uhlen M, Nygren PA (1997) Binding proteins selected from combinatorial libraries of an alpha-helical bacterial receptor domain. Nature Biotechnol 15: $772-$ 777.

Nygren PA (2008) Alternative binding proteins: affibody binding proteins developed from a small three-helix bundle scaffold. FEBS $J$ 275: 2668-2676.

Nygren PA, Uhlen M (1997) Scaffolds for engineering novel binding sites in proteins. Curr Opin Struct Biol 7: 463-469.

Orlova A, Magnusson M, Eriksson T.L, Nilsson M, Larsson B, Hoiden-Guthenberg I, Widstrom C, Carlsson J, Tolmachev V, Stahl S, Nilsson FY (2006) Tumor imaging using a picomolar affinity HER2 binding affibody molecule. Cancer Res 66: 4339-4348.

Russel M LH, Clackson T (2004) Introduction to phage biology and phage display. In Phage Display: A Practical Approach. Oxford university Press.

Sidhu SS, Kossiakoff AA (2007) Exploring and designing protein function with restricted diversity. Current Opin Chem Biol 11: 347-354.

Skerra A (2007) Alternative non-antibody scaffolds for molecular recognition. Current Opin Biotechnol 18: 295-304.

Smith GP (1985) Filamentous fusion phage: novel expression vectors that display cloned antigens on the virion surface. Science 228: 1315-1317.

Smith GP, Scott JK (1993) Libraries of peptides and proteins displayed on filamentous phage. Methods Ensymol 217: 228-257.

Steiner D, Forrer P, Pluckthun A (2008) Efficient selection of DARPins with sub-nanomolar affinities using SRP phage display. $J$ Mol Biol 382: 1211-1227.

Steiner D, Forrer P, Stumpp MT, Pluckthun A (2006) Signal sequences directing cotranslational translocation expand the range of proteins amenable to phage display. Nat Biotechnol 24: 823-831.

Tamaskovic R, Simon M, Stefan N, Schwill M, Pluckthun A (2012) Designed ankyrin repeat proteins (DARPins) from research to therapy. Methods Enzymol 503: 101-134. 
Wahlberg E, Lendel C, Helgstrand M, Allard P, Dincbas-Renqvist V, Hedqvist A, Berglund H, Nygren PA, Hard T (2003) An affibody in complex with a target protein: structure and coupled folding. Proc Natl Acad Sci USA 100: 3185-3190.

Wikman M, Steffen A.C, Gunneriusson E, Tolmachev V, Adams G.P, Carlsson J, Stahl S (2004) Selection and characterization of HER2/ neu-binding affibody ligands. Protein Engineering Design \& Selection 17: 455-462.

Wojcik J, Hantschel O, Grebien F, Kaupe I, Bennett K.L, Barkinge J, Jones R.B, Koide A, Superti-Furga G, Koide S (2010) A potent and highly specific FN3 monobody inhibitor of the Abl SH2 domain. Nat Struct Mol Biol 17: 519-527.

Zahnd C, Pecorari F, Straumann N, Wyler E, Pluckthun A (2006) Selection and characterization of Her2 binding-designed ankyrin repeat proteins. I Biol Chem 281 35167-35175.

Zahnd C, Wyler E, Schwenk JM, Steiner D, Lawrence MC, McKern NM, Pecorari F, Ward CW, Joos TO, Pluckthun A (2007) A designed ankyrin repeat protein evolved to picomolar affinity to Her2. J Mol Biol 369: 1015-1028. 